\title{
Stainless steel structures in fire
}

\author{
L. Gardner \\ BEng, MSc, DIC, PhD, CEng, MICE, MIStructE
}

Lecturer in Structural Engineering, Corresponding author, Department of Civil and Environmental Engineering, South Kensington Campus, Imperial College London, SW7 2AZ, UK. Email: Leroy.gardner@imperial.ac.uk

\begin{abstract}
The initial material cost of structural stainless steel is about four times that of structural carbon steel, due largely to the expense of the alloying elements and the relatively low volume of production. Given broadly similar structural performance, additional areas of benefit need to be identified and exploited in order to establish stainless steel as a viable alternative material for construction. In addition to the familiar benefits of corrosion resistance, low maintenance, high residual value and aesthetics, one such area is fire resistance. Stainless steel generally displays superior strength and stiffness retention at elevated temperature, but also exhibits greater thermal expansion. This paper describes experimental, numerical and analytical investigations into the elevated temperature response of stainless steel structures. Comparisons are made with the behaviour of carbon steel structures in fire and proposals for improved structural fire resistant design guidance for stainless steel are described.
\end{abstract}

\section{INTRODUCTION}

Recent years have seen significant research into the response of structural stainless steel components, enabling the development and expansion of dedicated design guidance. Provisions for stainless steel are now made in design standards in Europe, North America, Australia/ New Zealand and Japan. An increase in practical applications of the material in 
construction has resulted [1, 2, 3], an example of which, the Sanomatalo building in Helsinki, is shown in Fig. 1. However, despite considerable progress in the publication of room temperature design guidance, design rules for elevated temperatures are scarce, with only the European Standard offering guidance. Some background information is also provided as an Informative Annex in the Australia/New Zealand Standard.

The mechanical and thermal properties of stainless steel differ from those of carbon steel due to variation in chemical composition between the materials. This has implications on temperature development, strength and stiffness retention and thermal expansion, influencing the response of individual structural members and structural assemblages. In comparison with carbon steel, stainless steel generally offers superior strength and stiffness retention at elevated temperatures, but also greater thermal expansion. The fire resistance of stainless steel was a decisive factor in its specification for the structure of a flue system to extract smoke gases in the fourth road tunnel project under the River Elbe in Hamburg [4]. Recent developments, including fire testing, numerical modelling and the development of elevated temperature design guidance for stainless steel structures are described in this paper.

\section{MATERIAL RESPONSE AT ELEVATED TEMPERATURES}

\subsection{Introduction}

Material properties and their response to elevated temperatures form an essential part of structural fire design. Of primary importance are the elevated temperature stress-strain characteristics, thermal expansion, thermal conductivity, specific heat and unit mass. A comparison between these properties for stainless steel and carbon steel is presented in the following sub-sections. Additionally, the two key parameters for the determination of 
temperature development in structural members, namely, the convective heat transfer coefficient and the emissivity (absorptivity) are introduced. More detailed discussion of the elevated temperature material properties of stainless steel are given in [5].

\subsection{Strength and stiffness retention}

The ability of a material to retain strength and stiffness at elevated temperature is crucial for achieving fire resistant structures. Whilst there exists a large volume of elevated temperature material data for stainless steel, these have been primarily generated for its service use in applications such as boilers and pressure vessels. Consequently, test results are generally limited to low strain levels, relatively low temperatures (around $550^{\circ} \mathrm{C}$ ) and are primarily isothermal; the results are therefore of limited use for structural fire engineering purposes. Material behaviour at elevated temperatures was studied as part of the ECSC project 'Development of the use of stainless steel in construction', with data generated for a range of stainless steel grades, based on a programme of isothermal and anisothermal tests [6, 7]. Other material studies of stainless steel at temperatures concurrent with structural fire design (up to $900^{\circ} \mathrm{C}$ ) have also been conducted $[8,9,10]$. The studies have shown that, at elevated temperatures, stainless steel offers better retention of strength and stiffness than carbon steel, due to the beneficial effects of the alloying elements. A comparison of the elevated temperature performance of stainless steel and structural carbon steel is presented in Figs 2 and 3; the data are given in EN 1993-1-2 (2005) [11] and the Euro Inox/SCI Design Manual for Structural Stainless Steel [12], both of which are based on the test results reported in [6, 7, 8, 9]. The strength reduction factors shown in Fig. 2 are for grade 1.4301 (304) austenitic stainless steel, the most widely adopted grade for structural applications, whereas the stiffness reduction factors are common to all grades (austenitic, ferritic and duplex) included in the design guidance. Strength reduction factors are defined at two strain levels: $\mathrm{k}_{2, \theta}$ is the 
elevated temperature strength at $2 \%$ total strain $\mathrm{f}_{2, \theta}$, normalised by the room temperature $0.2 \%$ proof strength $f_{y}$, whilst $k_{0.2 p, \theta}$ is the elevated temperature $0.2 \%$ proof strength $f_{0.2 p, \theta}$, normalised by the room temperature $0.2 \%$ proof strength $f_{y}$. EN 1993-1-2 utilises the elevated temperature strength at $2 \%$ strain for the design of Class 1,2 and 3 cross-sections, whilst the elevated temperature $0.2 \%$ proof strength is employed for Class 4 cross-sections. At low temperatures, stainless steel has a reduction factor $\mathrm{k}_{2, \theta}$ of greater than unity (see Fig. 2) due to use of the $2 \%$ strain limit at elevated temperatures and the substantial strain hardening that stainless steel exhibits. The stiffness reduction factor $\mathrm{k}_{\mathrm{E}, \theta}$ is defined as the elevated temperature initial tangent modulus $\mathrm{E}_{\theta}$, normalised by the initial tangent modulus at room temperature $E_{a}$ (see Fig. 3). It should be noted that the minimum specified room temperature $0.2 \%$ proof strength for the most common structural grades of austenitic stainless steel typically ranges between 210 and $240 \mathrm{~N} / \mathrm{mm}^{2}$, whilst the Young's modulus is 200000 $\mathrm{N} / \mathrm{mm}^{2}$. However, the most widely used structural stainless steel products are cold-formed, and strain hardening during the forming processes often results in significant material strength enhancements. These strength enhancements are likely to be degraded following prolonged exposure to high temperatures. Thus, after a severe fire, the mechanical properties of the affected members will approach those of the annealed material. Figs 2 and 3 demonstrate the superior strength and stiffness retention of stainless steel, particularly at temperatures associated with structures in fire. For a fire resistance of 30 minutes, material will be exposed to temperatures in excess of $700^{\circ} \mathrm{C}$, following the standard fire curve of ISO 834-1 (1999) [13] and EN 1991-1-2 (2002) [14].

\subsection{Thermal properties}

This sub-section compares the key physical and thermal properties for elevated temperature behaviour (thermal conductivity, specific heat, unit mass and thermal expansion) of stainless 
steel and carbon steel. The variation of thermal conductivity with temperature is distinctly different for stainless steel as compared to carbon steel. The thermal conductivity of carbon steel is about $53 \mathrm{~W} / \mathrm{mK}$ at room temperature and reduces steadily with temperature to a value of $27 \mathrm{~W} / \mathrm{mK}$ by approximately $800^{\circ} \mathrm{C}$. In this temperature region $\left(723^{\circ} \mathrm{C}\right)$ a phase transformation occurs beyond which the thermal conductivity remains constant. The thermal conductivity of stainless steel is generally lower than that of carbon steel, rising steadily with temperature from a value of about $15 \mathrm{~W} / \mathrm{mK}$ at room temperature to a value of about 30 $\mathrm{W} / \mathrm{mK}$ at $1200^{\circ} \mathrm{C}$. The relationship is also continuous with temperature since no phase transformation occurs in austenitic stainless steel upon heating. The effect of lower thermal conductivity will be to cause more localised temperature development in a steel frame, though it is not believed that the differences in thermal conductivity between stainless steel and carbon steel has any significant influence on the general fire performance of a structure.

Specific heat (or specific heat capacity) is the amount of heat per unit mass of a material required to raise the temperature by one degree, and is clearly an important property in controlling the temperature development in a structural member. The specific heat of stainless steel increases steadily with temperature and shows no marked discontinuities (due to the absence of any phase change). The specific heat of carbon steel is, on average, slightly higher than stainless steel, and shows the latent heat of a phase change in the region of $723^{\circ} \mathrm{C}$. On average, the specific heat of carbon steel is approximately $600 \mathrm{~J} / \mathrm{kgK}$, as compared to approximately $550 \mathrm{~J} / \mathrm{kgK}$ for stainless steel.

The Euro Inox/SCI Design Manual for Structural Stainless Steel [12] and EN 1993-1-2 [11] state that the unit mass (density) of both carbon steel and stainless steel may be assumed to be independent of temperature and taken as $7850 \mathrm{~kg} / \mathrm{m}^{3}$. 
Fig. 4 shows a comparison of the thermal expansion of carbon steel and stainless steel as given in EN 1993-1-2. The figure shows that stainless steel expands with temperature to a greater extent, up to $50 \%$ more, than carbon steel. The effect of the higher thermal expansion has not been observed directly since no tests have been conducted on restrained stainless steel members or frames in fire. The implications of the higher degree of thermal expansion of stainless steel are investigated in Section 5 of this paper.

\subsection{Temperature development}

Accurate and efficient determination of the temperature development within a structural member upon subjection to fire is paramount. Temperature development in unprotected and uniformly heated steelwork is determined in EN 1993-1-2 [11] using the simple calculation model of Eq. 1 , in which $\Delta \theta_{\mathrm{a}, \mathrm{t}}$ is the increase in temperature $\left({ }^{\circ} \mathrm{C}\right)$ in a time increment $\Delta \mathrm{t}$ (in seconds).

$$
\Delta \theta_{\mathrm{a}, \mathrm{t}}=\mathrm{k}_{\mathrm{sh}} \frac{\mathrm{A}_{\mathrm{m}} / \mathrm{V}}{\mathrm{c}_{\mathrm{a}} \rho_{\mathrm{a}}} \dot{\mathrm{h}}_{\mathrm{net}, \mathrm{d}} \Delta \mathrm{t}
$$

where $k_{s h}$ is the correction factor for the shadow effect, $A_{m} / V$ is the section factor $\left(m^{-1}\right)$, $c_{a}$ is the specific heat of the material, $\rho_{a}$ is the material density $\left(\mathrm{kg} / \mathrm{m}^{3}\right)$, and $\dot{\mathrm{h}}_{\text {net,d }}$ is the design value of the net heat flux per unit area $\left(\mathrm{W} / \mathrm{m}^{2} \mathrm{~K}\right)$, controlled by the convective heat transfer coefficient an the emissivity.

The convective heat transfer coefficient is not a material constant, but is known to be a function of the fluid properties, the flow parameters and the geometry of the surface of the 
heated object [15]. The convective heat transfer coefficient is also a function of temperature, and although convection will occur at all stages of a fire, it is particularly important at low temperatures where radiation levels are low. For use with the standard temperature-time curve, EN 1991-1-2 recommends a single convective heat transfer coefficient $\alpha_{c}$ of 25 $\mathrm{W} / \mathrm{m}^{2} \mathrm{~K}$. In EN 1991-1-2, this value is not dependent on the material, though alternative values are provided for different temperature-time curves (the hydrocarbon curve).

Radiative heat transfer is controlled by resultant emissivity. Emissivity is a dimensionless property that ranges between zero and unity, and depends on factors such as temperature, emission angle and wavelength. A common engineering assumption which is adopted in EN 1991-1-2 is that a surface's spectral emissivity does not depend on wavelength, and thus emissivity is taken as a constant. Tabulated emissivities for materials are widely available in literature, but show substantial variation depending, in particular, on the condition of the surface. In general, the emissivity of a polished metallic surface is very low, whilst the emissivity of dull, oxidised material approaches unity. EN 1993-1-2 adopts an emissivity $\varepsilon_{\mathrm{m}}$ of 0.7 for carbon steel and 0.4 for stainless steel. The suitability of the recommended values for the heat transfer coefficient and emissivity of structural stainless steel members has been assessed, based on the results of a series of temperature development tests on structural stainless steel sections, and a supporting numerical programme [5]. In total, twenty austenitic stainless steel specimens exposed to fire on all four sides and three specimens exposed on three sides (with a concrete slab on the fourth side), have been tested. All specimens were subjected to the standard fire curve defined by ISO 834-1 [13]. Fourteen specimens, tested solely to investigate the temperature development characteristics of stainless steel sections and exposed to fire on all four sides, were reported in [16]. Other temperature development data were acquired from full scale member tests conducted to determine the fire resistance of 
structural stainless steel components $[7,16,17,18]$. The deformation of the specimens during testing was assumed not to affect their temperature development. Based on a study of these results, revised values for the heat transfer coefficient and emissivity of structural stainless steel members exposed to fire were proposed. In the temperature development calculation model of EN 1993-1-2 (Eq. 1), it was proposed that emissivity be taken as 0.2 (in place of the currently adopted value of 0.4 ) and the heat transfer coefficient be taken as $35 \mathrm{~W} / \mathrm{m}^{2} \mathrm{~K}$ (in place of the currently adopted value of $\left.25 \mathrm{~W} / \mathrm{m}^{2} \mathrm{~K}\right)$. The revised values result in calculated temperature development characteristics that more accurately reflect observed behaviour.

\section{FIRE TESTS AND NUMERICAL MODELLING}

\subsection{Introduction}

Although knowledge of the degradation of material strength and stiffness is fundamental to understanding the performance of members in fire, full-scale elevated temperature member tests also enable the effects of instability, temperature gradients and full cross-sectional behaviour (including enhanced strength corner regions) to be studied. Owing to the impracticality and expense of generating comprehensive structural fire performance data through experimentation, a detailed, non-linear numerical modelling programme, using the finite element package ABAQUS [19], has also been performed.

\subsection{Fire testing}

A number of recent experimental studies of the response of unprotected stainless steel structural members exposed to fire have been performed. Fire tests on a total of 23 austenitic stainless steel columns [7, 16, 18, 20, 21] (where failure was by flexural buckling), 6 stub columns [22] and 6 laterally-restrained beams [7, 16, 21] have been reported. The nominal 
section sizes, cross-section classifications, boundary conditions, applied loads and critical temperatures for these tests have been collated and summarised in [23]. A selection of the tests has been replicated numerically, as described in section 3.3 of this paper, forming the basis for parametric studies. Deformed specimens tested as part of the ECSC project 'Development of the use of stainless steel in construction' [16] are shown in Figs 5 and 6.

Of the 23 column buckling tests, 4 had fixed boundary conditions whilst the remainder were pin-ended. All column buckling tests were performed on hollow sections (19 rectangular hollow sections (RHS) and 3 circular hollow sections (CHS)) with the exception of one Isection, made up of a pair of channel sections welded back-to-back. The 6 stub column tests were all Class 4 rectangular hollow sections. The 6 beam tests included one rectangular hollow section, 3 I-sections and 2 top-hat sections. All of the tested beams were supporting a concrete slab which provided full lateral restraint. There have been no tests on laterally unrestrained stainless steel beams in fire, though numerical studies have been performed by [24]. All tests were anisothermal, whereby the load was held at a constant level and the temperature was increased (generally following the standard fire curve of ISO 834-1 (1999) [13]) until failure.

\subsection{Numerical modelling}

A numerical modelling study was performed to gain further insight into the buckling response of stainless steel members in fire, and to investigate the influence of key parameters. The finite element software package ABAQUS [19] was employed throughout the study.

\subsubsection{Column buckling}


Analyses were conducted to simulate 12 column buckling fire tests - 4 fixed-ended and 2 pinended columns reported in [7, 16], and 6 pin-ended columns reported in [20]. The stainless steel members were modelled using the shell elements S4R, which have 4 corner nodes, each with 6 degrees of freedom, and are suitable for thick or thin shell applications [19]. A mesh convergence study was performed to identify an appropriate mesh density to achieve suitably accurate results whilst maintaining practical computation times. Test boundary conditions were replicated by restraining suitable displacement and rotation degrees of freedom at the column ends, and through the use of constraint equations. The replicated fire tests were performed anisothermally. This was reflected in the numerical modelling by performing the analyses in two steps: in the first step, load was applied to the column at room temperature, and in the second step, temperature was increased following the measured temperature-time relationships until failure. All material was stainless steel grade 1.4301 (304), and material modelling was based on a multi-linear fit to measured elevated temperature stress-strain data. Imperfections were incorporated into the models by means of superposition of local and global eigenmodes.

Sensitivity studies were performed to investigate the influence of imperfections, cold-worked corner material properties and partial protection of the column ends. The studies revealed that the models were relatively insensitive to variation in imperfections, showing negligible response to changes in local imperfection amplitude and exhibiting, on average, a 6\% reduction in critical temperature in response to variation of global imperfection amplitude from $\mathrm{L} / 2000$ to $\mathrm{L} / 500$ (where $\mathrm{L}$ is the column length). The majority of the modelled fire tests were performed on cold-formed sections, which exhibit strength enhancements in the corner regions - modelling of this strength enhancement, based on predictive expressions developed in [25], led to a $6 \%$ increase in critical temperature and improved agreement between test and 
finite element (FE) results. Some of the test arrangements included partial protection of the column ends from the direct effects of fire - inclusion of this protection in the FE models resulted in a 3\% increase in critical temperature and improved agreement between test and $\mathrm{FE}$ results. A comparison between the test and finite element results is given in Table 1. Overall, it was concluded that the described FE models are capable of replicating the non-linear large deflection response of structural stainless steel members in fire.

Parametric studies were conducted to assess variation in local cross-section slenderness, global member slenderness and load level. Results were compared against those predicted by EN 1993-1-2. Variation in cross-section slenderness was achieved by considering a range of cross-section thicknesses. The results showed that Class 1 to 3 sections behave similarly, and generally follow the EN 1993-1-2 design curve. For the Class 4 sections, however, agreement was poor. The reason for this is two-fold. Firstly, the load ratio is determined by normalising the applied load by the room temperature buckling resistance - for Class 4 sections, the room temperature buckling resistance is calculated on the basis of an effective section to account for local buckling; this results in higher load ratios. Secondly, EN 1993-1-2 specifies use of the strength reduction factor corresponding to the $0.2 \%$ proof stress $\mathrm{k}_{0.2 \mathrm{p}, \theta}$ for Class 4 crosssections, whilst Class 1 to 3 sections benefit from the use of a higher $2 \%$ strain limit and adopt $\mathrm{k}_{2, \theta}$. It may be concluded that the current treatment of Class 4 stainless steel sections in EN 1993-1-2 does not accurately reflect the behaviour predicted by the described FE models. Variation in member slenderness was achieved by considering a range of column lengths. As anticipated, there was a general trend showing that critical temperature reduces with increasing load ratio. The results also indicated that variation of critical temperature with load ratio is slenderness dependent. This would be expected since stocky columns are controlled primarily by material strength and its degradation, whilst slender columns are controlled 
primarily by material stiffness and its degradation. Since strength and stiffness do not degrade at the same rate with temperature it follows that the critical temperature of columns is slenderness dependent.

\subsubsection{Stub columns}

Six stub columns tests [22] were also modelled numerically, using the parameters described in the previous section. No global imperfection was included in the models, but local imperfections of magnitude proposed in [26] and corner strength enhancements extending to a distance of two times the material thickness based on the predictive expressions developed in [25] were employed. Boundaries conditions were prescribed to replicate those in the tests: all degrees of freedom were restrained at the unloaded ends of the stub columns, whilst all except vertical displacement were restrained at the loaded end. Constraint equations were applied to ensure that the nodes at the loaded end of the stub column moved in unison. A typical stub column model is shown in Fig. 7. Good agreement between test and FE results is shown in the comparisons of Table 2. Parametric studies were performed to further investigate crosssection behaviour, where variation in cross-section slenderness was achieved by varying the thickness of the stub columns. The test and parametric FE results are compared with existing and proposed design approaches in Section 4 of this paper.

\section{STRUCTURAL FIRE DESIGN}

The European provisions for the design of stainless steel members in fire largely follow the carbon steel rules, with the primary differences being in the material properties. The material properties of stainless steel have been incorporated into Annex C of EN 1993-1-2 [11] to extend the scope of this document to the design of stainless steel structures in fire. Results from all available tests on stainless steel columns and beams in fire have been compared to 
existing design guidance given in EN 1993-1-2 [11], the Euro Inox/ SCI Design Manual for Structural Stainless Steel [12] and proposed by CTICM/ CSM [27]. The comparisons generally revealed both conservatism and scatter of prediction in existing design methods, due, in part, to inconsistent treatment of buckling and inappropriate strain limits and member buckling curves. Revised recommendations are made herein.

At elevated temperatures, stainless steel displays superior material strength and stiffness retention in comparison to structural carbon steel (see Figs 2 and 3). Although independently important, the relationship between strength and stiffness at elevated temperature also has a significant influence on the buckling response of structural components. Currently, this concept is included in EN 1993-1-2 and the Euro Inox/ SCI Design Manual for Structural Stainless Steel for member buckling through the definition and use of an elevated temperature non-dimensional member slenderness $\bar{\lambda}_{\theta} \cdot \bar{\lambda}_{\theta}$ is defined by a modification of the room temperature non-dimensional slenderness $\bar{\lambda}$, as given by Eqs. (2) and (3).

$$
\begin{array}{rr}
\bar{\lambda}_{\theta}=\bar{\lambda}\left(\mathrm{k}_{2, \theta} / \mathrm{k}_{\mathrm{E}, \theta}\right)^{0.5} & \text { for Class } 1 \text { to } 3 \text { cross-sections } \\
\bar{\lambda}_{\theta}=\bar{\lambda}\left(\mathrm{k}_{0.2 \mathrm{p}, \theta} / \mathrm{k}_{\mathrm{E}, \theta}\right)^{0.5} & \text { for Class } 4 \text { cross-sections }
\end{array}
$$

The variation of $\left(\mathrm{k}_{\mathrm{E}, \theta} / \mathrm{k}_{2, \theta}\right)^{0.5}$ (where $\mathrm{k}_{2, \theta}$ is based on the $2 \%$ total strain limit) and $\left(\mathrm{k}_{\mathrm{E}, \theta} / \mathrm{k}_{0.2 \mathrm{p}, \theta}\right)^{0.5}$ (where $\mathrm{k}_{0.2 \mathrm{p}, \theta}$ is based on the $0.2 \%$ plastic strain limit) with temperature for stainless steel and carbon steel is shown in Fig. 8. Values of $\left(\mathrm{k}_{\mathrm{E}, \theta} / \mathrm{k}_{2, \theta}\right)^{0.5}$ or $\left(\mathrm{kE}_{\mathrm{E}, \theta} / \mathrm{k}_{0.2 \mathrm{p}, \theta}\right)^{0.5}$ less than unity lead to an increase in the non-dimensional member slenderness and represents greater propensity to buckling (rather than yielding) at elevated temperature than at room 
temperature. For values of $\left(\mathrm{kE}_{\mathrm{E}, \theta} / \mathrm{k}_{2, \theta}\right)^{0.5}$ or $\left(\mathrm{kE}_{\mathrm{E}, \theta} / \mathrm{k}_{0.2 \mathrm{p}, \theta}\right)^{0.5}$ greater than unity, as is the case for stainless steel at fire temperatures, the reverse is true.

In the treatment of local buckling at room temperature, the $\varepsilon$ factor is employed to allow for variation in material yield strength $\mathrm{f}_{\mathrm{y}}$. In fire, ENV 1993-1-2 (2001) [28] modified the $\varepsilon$ factor used in section classification to reflect that loss of strength and stiffness at elevated temperatures does not occur at the same rate. Thus, at elevated temperatures $\varepsilon$ was modified by the factor $\left(\mathrm{k}_{\mathrm{E}, \theta} / \mathrm{k}_{2, \theta}\right)^{0.5}$ and was defined by Eq. (4).

$$
\varepsilon=\left[\left(\frac{235}{f_{y}}\right)\left(\frac{k_{E, \theta}}{k_{2, \theta}}\right)\right]^{0.5}
$$

From Fig. 8, it may be seen that for the majority of the elevated temperature range, carbon steel has values of $\left(\mathrm{k}_{\mathrm{E}, \theta} / \mathrm{k}_{2, \theta}\right)^{0.5}$ less than unity and is therefore more susceptible to buckling (as opposed to yielding) than at room temperature; neglecting this feature leads to unsafe predictions. To simplify calculations, this factor was set as a constant of 0.85 (which was deemed an acceptably safe average value at fire limit state) in EN 1993-1-2 (2005), for both carbon steel and stainless steel. Clearly from Fig. 8, however, this factor is inappropriate for stainless steel. The Euro Inox/ SCI Design Manual for Structural Stainless Steel [12] effectively employs a modification factor of unity by adopting the room temperature classification for elevated temperature. This is more appropriate than the Eurocode 3 treatment, but still, does not correctly reflect the variation of strength and stiffness at elevated temperature exhibited by stainless steel. 
It is proposed that the true variation of stiffness and strength at elevated temperature be utilised in cross-section classification and in the determination of effective section properties for stainless steel structures in fire. Thus, the $\varepsilon_{\theta}$ factors defined by Eqs. (5) and (6) should be determined at the critical temperature, and hence used to re-classify the cross-section. Eq. (5) may be applied to cross-sections that are Class 1 or 2 at room temperature and utilises the $2 \%$ strain limit, whilst Eq. (6) applies to cross-sections that are Class 3 or 4 at room temperature and utilises the $0.2 \%$ plastic strain limit. Eq. (6) also applies in the determination of effective section properties. The notation $\varepsilon_{\theta}$ is introduced to differentiate from the $\varepsilon$ factor used for room temperature design.

$$
\begin{aligned}
& \varepsilon_{\theta}=\left[\left(\frac{235}{\mathrm{f}_{\mathrm{y}}} \frac{\mathrm{E}}{210000}\right)\left(\frac{\mathrm{k}_{\mathrm{E}, \theta}}{\mathrm{k}_{2, \theta}}\right)\right]^{0.5}=\varepsilon\left(\frac{\mathrm{k}_{\mathrm{E}, \theta}}{\mathrm{k}_{2, \theta}}\right)^{0.5} \text { for Class } 1 \text { and } 2 \text { sections } \\
& \varepsilon_{\theta}=\left[\left(\frac{235}{\mathrm{f}_{\mathrm{y}}} \frac{\mathrm{E}}{210000}\right)\left(\frac{\mathrm{k}_{\mathrm{E}, \theta}}{\mathrm{k}_{0.2 \mathrm{p}, \theta}}\right)\right]^{0.5}=\varepsilon\left(\frac{\mathrm{k}_{\mathrm{E}, \theta}}{\mathrm{k}_{0.2 \mathrm{p}, \theta}}\right)^{0.5} \text { for Class } 3 \text { and } 4 \text { sections }
\end{aligned}
$$

From Fig. 8, is may be seen that the factors $\left(\mathrm{k}_{\mathrm{E}, \theta} / \mathrm{k}_{2, \theta}\right)^{0.5}$ and $\left(\mathrm{k}_{\mathrm{E}, \theta} / \mathrm{k}_{0.2 \mathrm{p}, \theta}\right)^{0.5}$ for stainless steel are greater than unity at elevated temperatures. The result of cross-section re-classification and the re-determination of effective section properties at the critical temperature will therefore be beneficial, and ignoring this process will be conservative. Cross-sections that are Class 4 at room temperature may become fully effective at elevated temperatures due to relaxation of the classification limits through $\varepsilon_{\theta}$. It is further proposed that in the determination of cross-section and member resistance in fire, the strength reduction factor be based on the $2 \%$ strain limit $\left(\mathrm{k}_{2, \theta}\right)$ for Class 1 and 2 cross-sections and the $0.2 \%$ plastic strain limit $\left(\mathrm{k}_{0.2 \mathrm{p}, \theta}\right)$ for Class 3 and 4 cross-sections. Use of the strength at $2 \%$ strain for Class 3 
cross-sections, as is proposed in existing design guidance seems unjustified, since local buckling would be expected before this strain level is reached.

Theoretical justification for the use of $\varepsilon_{\theta}$ has been described above. Table 3 compares the results of stub column tests and finite element models with the existing design approach of EN 1993-1-2 and that proposed herein, utilising $\varepsilon_{\theta}$. The results indicate that the proposed approach offers significant improvement in the prediction of elevated temperature resistance over the existing approach in EN 1993-1-2.

Having established a more consistent basis for the treatment of buckling of stainless steel elements in fire, comparison was made with all the test results (including long columns and beams) summarised in Section 3. For columns, a revised buckling curve has also been proposed to provide a mean fit to the test results, which is acceptable at fire limit state. This was achieved by adopting the general form of the room temperature buckling curves of Eurocode 3 Part 1.1, and selecting appropriate values of the imperfection parameter $\alpha$ and the limiting slenderness $\bar{\lambda}_{0}$. A comparison of the resulting fire buckling curve with $\alpha=0.55$ and $\bar{\lambda}_{0}=0.2$ is shown in Fig. 9. Following analysis of the results it was revealed that one of the columns, Class 4 at room temperature, becomes Class 2 at elevated temperature, and its resistance is over-predicted by the proposed method. In the absence of further test results, it is recommended that cross-sections that are Class 4 at room temperature cannot be promoted beyond Class 3 at elevated temperatures.

For column buckling (23 tests), the mean proposed divided by test resistance is 1.00 with a coefficient of variation (COV) of 0.15 . For stub columns (6 tests), the mean proposed divided by test resistance is 0.91 with a coefficient of variation (COV) of 0.15 , whilst for beams (6 
tests), the mean proposed divided by test resistance is 0.84 with a coefficient of variation (COV) of 0.19 . The proposed treatment offers a more rational approach to the fire design of structural stainless steel columns and beams, yielding an improvement of $6 \%$ for column buckling resistance, $28 \%$ for stub column (cross-section) resistance and 14\% for in-plane bending resistance over the current Eurocode methods. Further details are given in [23].

\section{THERMAL EXPANSION}

Stainless steel expands with temperature to a greater extent, up to $50 \%$ more, than carbon steel (see Fig. 4). Typically during component tests in fire (such as those described herein), structural members will be free to expand against the applied load, and thus no additional load is induced due to this expansion. However, in structural frames, where continuity exists between members and often fire is relatively localised, thermal expansion may be restrained by other (stiffer) parts of the structure, resulting in additional member loading. The effect of the higher thermal expansion has not been observed directly since no tests have been conducted on restrained stainless steel members or frames in fire. Given the greater thermal expansion and the ability to retain strength and stiffness to higher temperatures, additional forces will generally be experienced by restrained stainless steel structural members. The severity of the additional member forces will depend on the applied loading arrangement and on the degree of rotational and translational restraint present. Further consequences of thermal expansion may include higher axial and lateral member deformations leading to greater second order effects. However, recent studies of the large deflection behaviour of restrained columns [29] and beams [30] have indicated that provided the integrity of the fire compartment is maintained and localised column failure (which will not occur until the resistance drops to below the applied load level) is acceptable, the effects of thermal expansion may not be very severe. 
Numerical studies have been performed to investigate the response of restrained stainless steel columns and beams. The finite element software package ABAQUS was employed throughout the study. For columns, initial comparisons were made against the findings of Franssen [29], who examined the response of restrained carbon steel columns. Members were modelled using the beam element type of B31, which is a 2-node linear beam. An element size (length) of $20 \mathrm{~mm}$ was used throughout the study, with the column length being $4 \mathrm{~m}$ and the load ratio 0.4. Pin-ended boundary conditions were replicated by restraining suitable displacement and rotation degrees of freedom at the column ends. A small lateral load was applied at the mid-height of the columns to represent member imperfections. The carbon steel columns were grade S235, whilst grade 1.4301 was assumed for the stainless steel columns - this grade is commonly adopted and has comparable room temperature properties $\left(f_{y}=210 \mathrm{~N} / \mathrm{mm}^{2}\right.$ and $\mathrm{E}=200000 \mathrm{~N} / \mathrm{mm}^{2}$ ) to those of S235 carbon steel. Thermal properties, including thermal expansion for both carbon steel and stainless steel were taken from EN 1993-1-2 (2005) [11]. Different levels of axial restraint were modelled using axial springs, with stiffnesses defined as fixed proportions of the axial stiffness of the column $(=\mathrm{EA} / \mathrm{L}$, where $\mathrm{E}$ is Young's modulus, $\mathrm{A}$ is the cross-sectional area and $\mathrm{L}$ is the member length). The results are summarised in Table 4, where good agreement between Franssen's models and those developed in the present study may be seen. From the results, it may be concluded that for low levels of axial restraint, stainless steel columns have higher critical temperatures than equivalent carbon steel columns due to the superior strength and stiffness retention. However, for high levels of axial restraint, the greater thermal expansion that stainless steel exhibits results in greater axial forces and lower critical temperatures. The actual level of axial column restraint that exists in structural frames has been estimated to be 2-3\% [31]. 
To investigate the response of restrained stainless steel beams in fire, finite element models were initially validated against existing tests and numerical models of restrained carbon steel beams in fire [32, 30]. Once validated against the carbon steel results, the physical and thermal properties of stainless steel were introduced. For large deflections, which occur at high temperatures, the load carrying mechanism of steel beams changes from bending to catenary action provided sufficient axial restraint is present. Utilisation of this additional load carrying capacity relies on the provision of axial restraint without compromising the surrounding structure and the allowance of large deflections whilst maintaining the integrity of the fire compartment.

In general, the generated FE results were found to be in good agreement with the existing test and numerical results; details of the comparisons have been reported in [33]. The introduction of stainless steel material properties showed improved performance for low levels of axial restraint, but for higher levels of restraint the behaviour of beams of the two materials showed greater parity. Fig. 10 compares the vertical deflection versus temperature response of restrained carbon steel and stainless steel beams with axial restraint of stiffness equal to $0.3 \mathrm{EA} / \mathrm{L}$, and two levels of rotational restraint. The vertical deflection arises from a combination of in-plane bending from the applied vertical loading and buckling due to the axial compression resulting from the restrained thermal expansion. The higher rotational restraint reduces both of these deflection components, but this leads to higher axial forces, which will be transmitted to the adjacent parts of the structure. From Fig. 10 it may be seen that at low temperatures, the stainless steel beams show larger deflections than the corresponding carbon steel beams - this is due to the buckling induced deflections resulting from the higher axial forces (due to the greater thermal expansion) and the marginally lower room temperature Young's modulus. At higher temperatures, however, the carbon steel beams exhibit higher deflections due to the rapid loss of material stiffness. Assessment of the critical temperature of axially restrained beams and utilisation of catenary action 
needs to be performed carefully with due allowance for the effects on the surrounding structure and the levels of deflections that are tolerable. Recent advancements in this area have been reported in [34].

\section{CONCLUSIONS}

Stainless steel exhibits different physical and thermal properties to structural carbon steel due to the variation in chemical composition. Principally, this results in stainless steel offering better retention of strength and stiffness at elevated temperatures, which is reflected in EN 1993-1-2 (2005), and greater thermal expansion. However, in addition to knowledge of the independent degradation of material strength and stiffness at elevated temperatures, the relationship between strength and stiffness is also important, since this defines susceptibility to buckling. This concept has been recognised in EN 1993-1-2 for member buckling by the use of an elevated temperature non-dimensional member slenderness, but for local buckling of stainless steel sections, current codified treatment is inappropriate.

The results of a total of 23 column buckling fire tests, 6 stub column fire tests and 6 fire tests on laterally-restrained beams have been collated and analysed. A selection of the tests has been replicated numerically, where the importance of local and global initial geometric imperfections, residual stresses, enhanced strength corner properties and partial protection of the member ends has been investigated. From the comparisons between test and numerical results, it may be concluded that the described FE models are capable of replicating the nonlinear large deflection response of structural stainless steel members in fire.

By considering both the experimentally and numerically generated structural performance data, it was concluded that making explicit allowance for the true variation between strength 
and stiffness at elevated temperatures resulted in improved prediction of the local and global buckling of stainless steel columns and beams. The primary implications of the proposals made herein are on cross-section classification and the determination of effective section properties. In addition to this, a revised buckling curve for stainless steel in fire and consistent strain limits have been proposed. These revisions have led to a more efficient and consistent treatment of buckling of stainless steel columns in fire. Improvements of $6 \%$ for column buckling resistance, $28 \%$ for stub column (cross-section) resistance and $14 \%$ for inplane bending resistance over the current Eurocode methods are achieved.

The significance of the greater thermal expansion exhibited by stainless steel was assessed by considering the elevated temperature performance of axially restrained columns and beams. Numerical models were initially validated against existing experimental and numerical studies on carbon steel, after which the physical and thermal properties of stainless steel were introduced. Overall, for low levels of axial restraint, stainless steel displays better fire performance than carbon steel due to the superior retention of strength and stiffness, whilst for higher levels of axial restraint the additional forces induced due to restrained thermal expansion become more detrimental for the stainless steel members.

\section{ACKNOWLEDGEMENTS}

The author would like to thank Kee Teong Ng and Chee Ho Wu of Imperial College London and Nancy Baddoo of the Steel Construction Institute for their contribution to this research.

\section{REFERENCES}

[1] Gardner, L. (2005). The use of stainless steel in structures. Progress in Structural Engineering and Materials. 7(2). 45-55. 
[2] Baddoo, N. R., Burgan, R. and Ogden, R. Architects' Guide to Stainless Steel. (1997). SCI-P-179. The Steel Construction Institute, UK.

[3] Gardner, L. (2006). Aesthetics, economics and design of stainless steel structures. Proceedings of the Eight International Conference on Steel, Space and Composite Structures. 15th - 17th May, 2006. Kuala Lumpur, Malaysia, pp. 97-104.

[4] Stalatube. (2007). Examples of the use of stainless steel in different sectors of industry. http://www.stalatube.com/en/products/references.html. Accessed January 2007.

[5] Gardner, L. and Ng, K. T. (2006). Temperature development in structural stainless steel sections exposed to fire. Fire Safety Journal. 41(3), 185-203.

[6] Zhao, B. (2000). Material behaviour at elevated temperatures: Work package 5.1. ECSC project 'Development of the use of stainless steel in construction'. Contract No. 7210 SA/ 842. The Steel Construction Institute, UK.

[7] Gardner, L. and Baddoo, N. R. (2006). Fire testing and design of stainless steel structures. Journal of Constructional Steel Research. 62(6), 532-543.

[8] Ala-Outinen, T. (1996). Fire resistance of austenitic stainless steels Polarit 725 (EN 1.4301) and Polarit 761 (EN 1.4571) VTT Research Notes 1760, Espoo, Finland.

[9] Hoke, J. H. (1977). Handbook of Stainless Steels. McGraw-Hill. 
[10] Chen, J. and Young, B. (2006). Stress-strain curves for stainless steel at elevated temperatures. Engineering Structures. 28(2), 229-239.

[11] EN 1993-1-2. (2005). Eurocode 3: Design of steel structures - Part 1.2: General rules Structural fire design. CEN.

[12] Design Manual for Structural Stainless Steel. (2002). Second edition. Euro Inox and the Steel Construction Institute. Building series, Volume 3.

[13] ISO 834-1. (1999). Fire-resistance tests - Elements of building construction - Part 1: General requirements. International Organization for Standardization, Geneva.

[14] EN 1991-1-2. (2002). Eurocode 1: Actions on structures - Part 1.2: General actions Actions on structures exposed to fire. CEN.

[15] Drysdale, D. (1985). An introduction to fire dynamics. 2nd Ed.. John Wiley \& Sons Ltd.

[16] Baddoo, N. R. and Gardner, L. (2000). Member behaviour at elevated temperatures: Work package 5.2. ECSC project 'Development of the use of stainless steel in construction'. Contract No. 7210 SA/842. The Steel Construction Institute, UK.

[17] Baddoo, N. R. and Burgan, B. A. (1998). Fire resistance design of austenitic stainless steel. Paper No. 243. 2nd World Conference on Steel Structures, San Sebastian. May 1998. 
[18] Ala-Outinen, T. (1999). Fire resistance of stainless steel structures. Proceedings of the Second European Conference on Steel Structures (Eurosteel 1999). Prague, Czech Republic, 26th-29th May, 1999. 165-168.

[19] ABAQUS (2003). ABAQUS/ Standard User’s Manual Volumes I-III and ABAQUS CAE Manual. Version 6.4. Hibbitt, Karlsson \& Sorensen, Inc. Pawtucket, USA.

[20] Ala-Outinen, T. and Oksanen, T. (1997) Stainless steel compression members exposed to fire. VTT Research Notes 1864, Espoo, Finland.

[21] Zhao, B. and Blanguernon, A. (2004). Member Tests in Fire and Structural Fire Design Guidance. Work package 6: Elevated Temperature Properties. ECSC project 'Structural design of cold-worked austenitic stainless steel'. Contract No. 7210-PR-318. The Steel Construction Institute, UK.

[22] Ala-Outinen, T. (2005). Members with Class 4 cross-sections in fire: Work package 3. ECSC project 'Stainless steel in fire (SSIF)'. Contract No. RFS-CR-04048. VTT. (Confidential).

[23] Ng, K. T. and Gardner, L. (2007). Buckling of stainless steel columns and beams in fire. Engineering Structures. 29(5), 717-730.

[24] Lopes, N., Vila Real, P. M. M., Simões da Silva, L. and Mirambell, E. (2006). Numerical modelling of the lateral-torsional buckling of stainless steel I-beams: comparison with 
Eurocode 3. Computational Methods in Engineering and Science, EPMESC X, 21st-23rd August, 2006, Sanya, Hainan, China.

[25] Ashraf, M., Gardner, L. and Nethercot, D. A. (2005). Strength enhancement of the corner regions of stainless steel cross-sections. Journal of Constructional Steel Research. 61(1), 3752.

[26] Gardner, L. and Nethercot, D. A. (2004). Numerical modelling of stainless steel structural components - A consistent approach. Journal of Structural Engineering, ASCE. 130(10), 1586-1601.

[27] CTICM/CSM (2005). Stainless steel column buckling behaviour at elevated temperatures - Comparison of Euro Inox and CTICM methods. Centro Sviluppo Materiali S.p.A.

[28] ENV 1993-1-2. (2001). Eurocode 3: Design of steel structures - Part 1.2: General rules Structural fire design. CEN.

[29] Franssen, J.-M. (2000). Failure temperature of a system comprising a restrained column submitted to fire. Fire Safety Journal. 34(2), 191-207.

[30] Yin, Y. Z. and Wang, Y. C. (2004). A numerical study of large deflection behaviour of restrained steel beams at elevated temperatures. Journal of Constructional Steel Research. 60(7), 1029-1047. 
[31]. Wang, Y. C. and Moore, D. B. (1994). Effect of thermal restraint on column behaviour in a frame. Proceedings of the Fourth International Symposium on Fire Safety Science (IAFSS), Ottawa, Canada. pp. 1055-1066.

[32] Liu, T. C. H., Fahad, M. K. and Davies, J. M. (2002). Experimental investigation of behaviour of axially restrained steel beams in fire. Journal of Constructional Steel Research. 58(9), 1211-1230.

[33] Ng, K. T. (2007). Stainless steel structures in fire. PhD thesis. Department of Civil and Environmental Engineering, Imperial College London.

[34] Wang, Y. C. and Yin, Y. Z. (2005). Feasibility of utilising catenary action to eliminate fire protection to steel beams. Proceedings of the Fourth International Conference on Advances in Steel Structures, 13th-15th June 2005, Shanghai, China. Vol. II, pp. 959-964. 


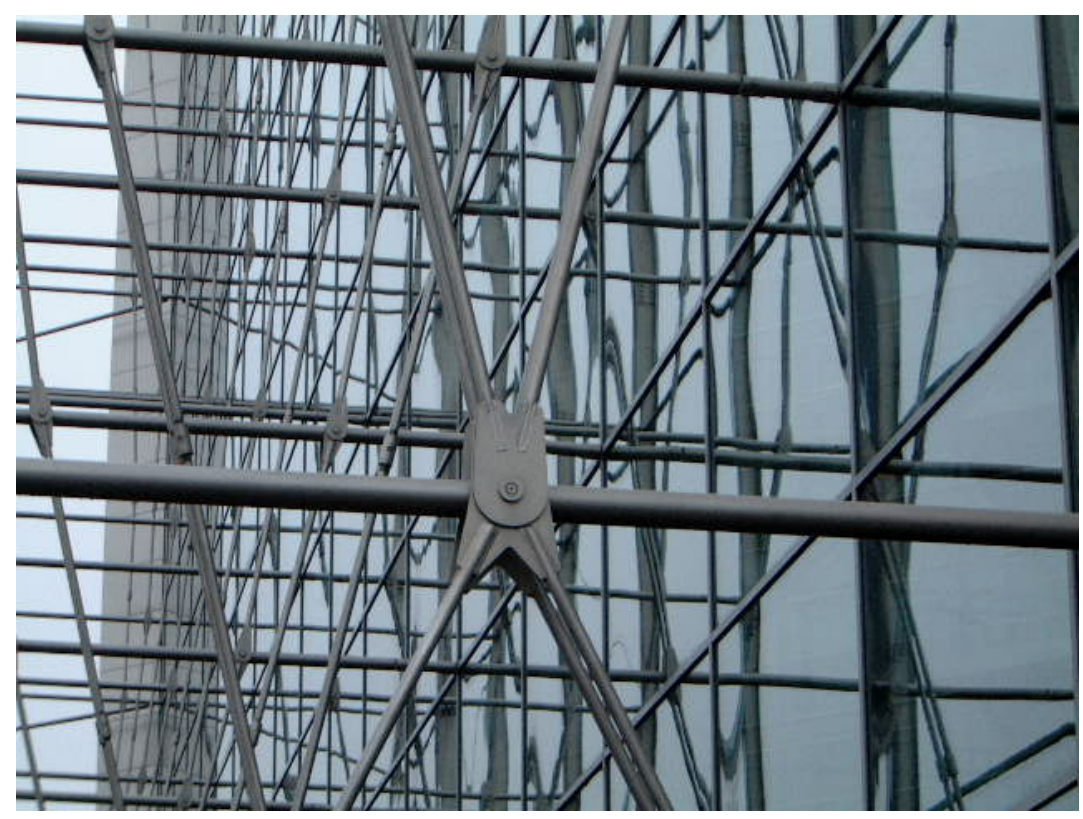

Fig. 1 - External stainless steel bracing system, Sanomatalo Building, Helsinki

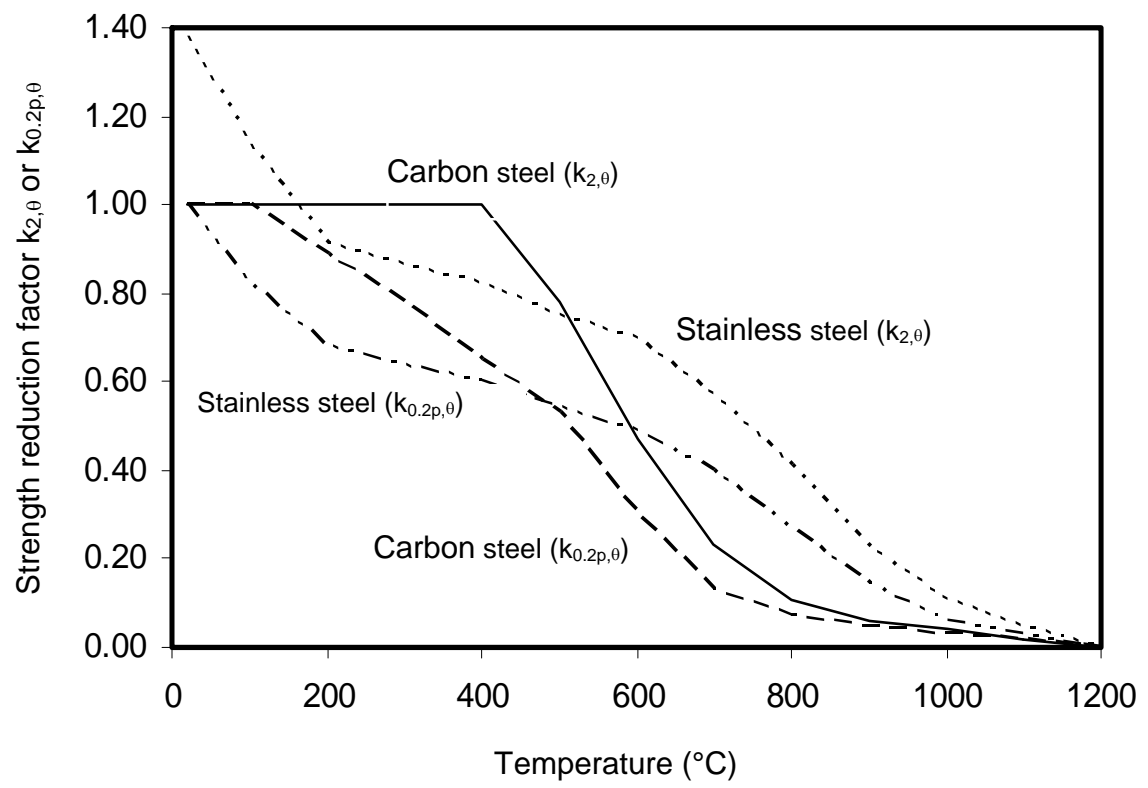

Fig. 2 - Strength reduction of stainless steel and carbon steel at elevated temperature 


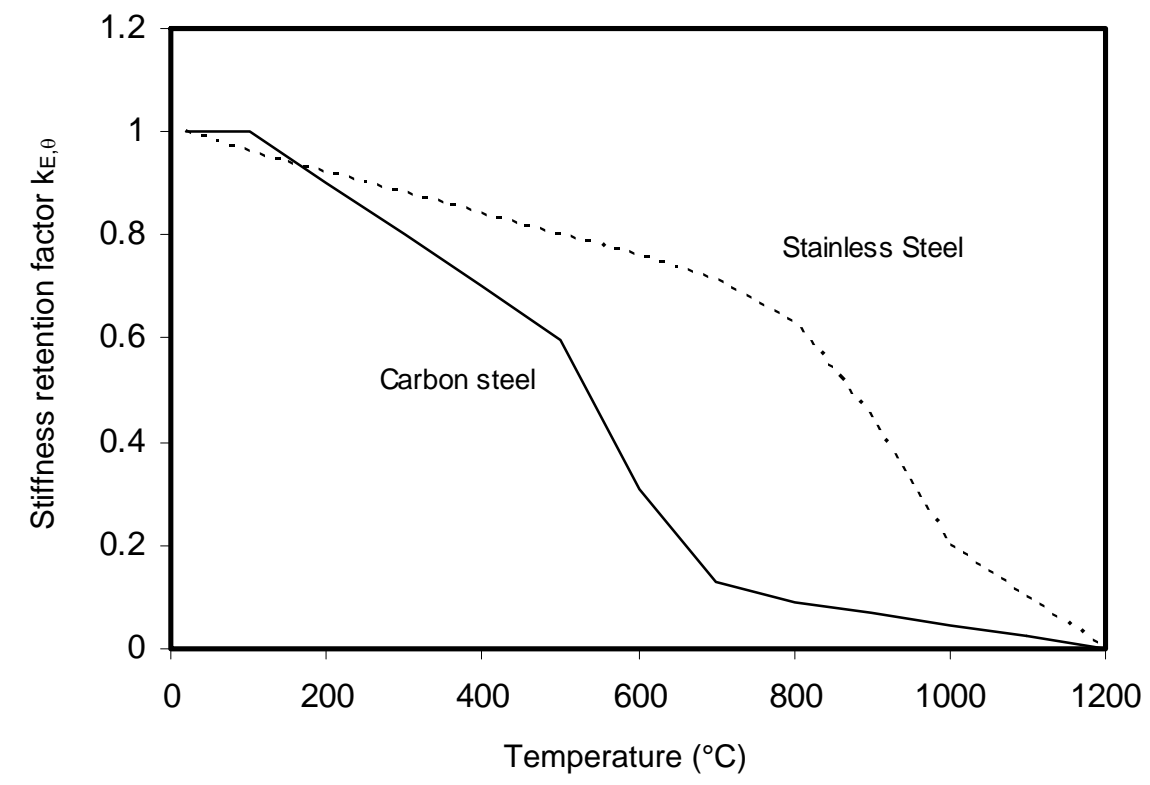

Fig. 3 - Stiffness reduction of stainless steel and carbon steel at elevated temperature

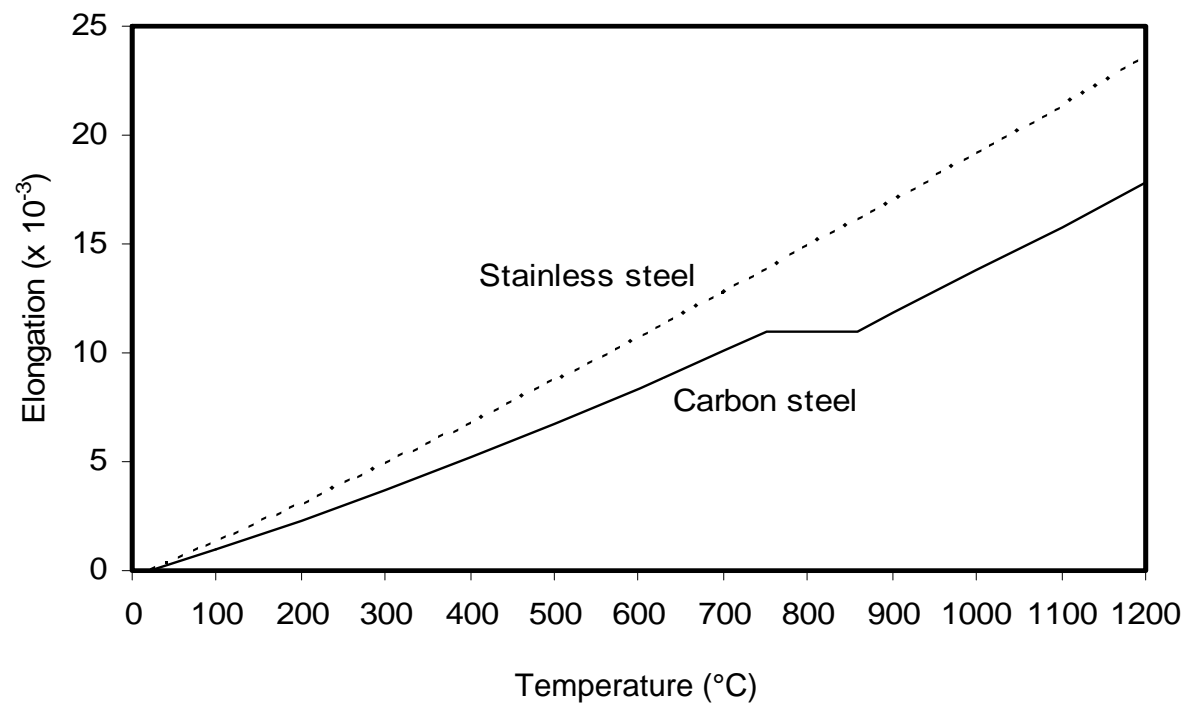

Fig. 4 - Thermal expansion of stainless steel and carbon steel at elevated temperature

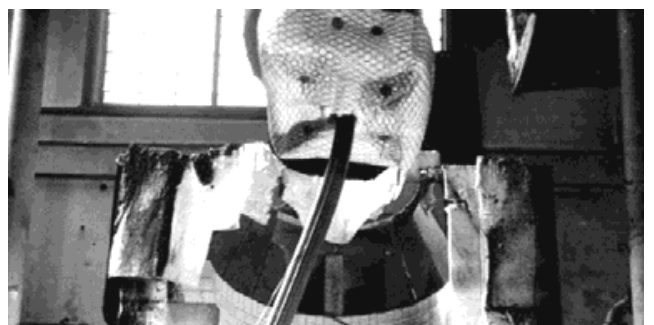


Fig. $5-100 \times 75 \times 6.0$ RHS column after testing

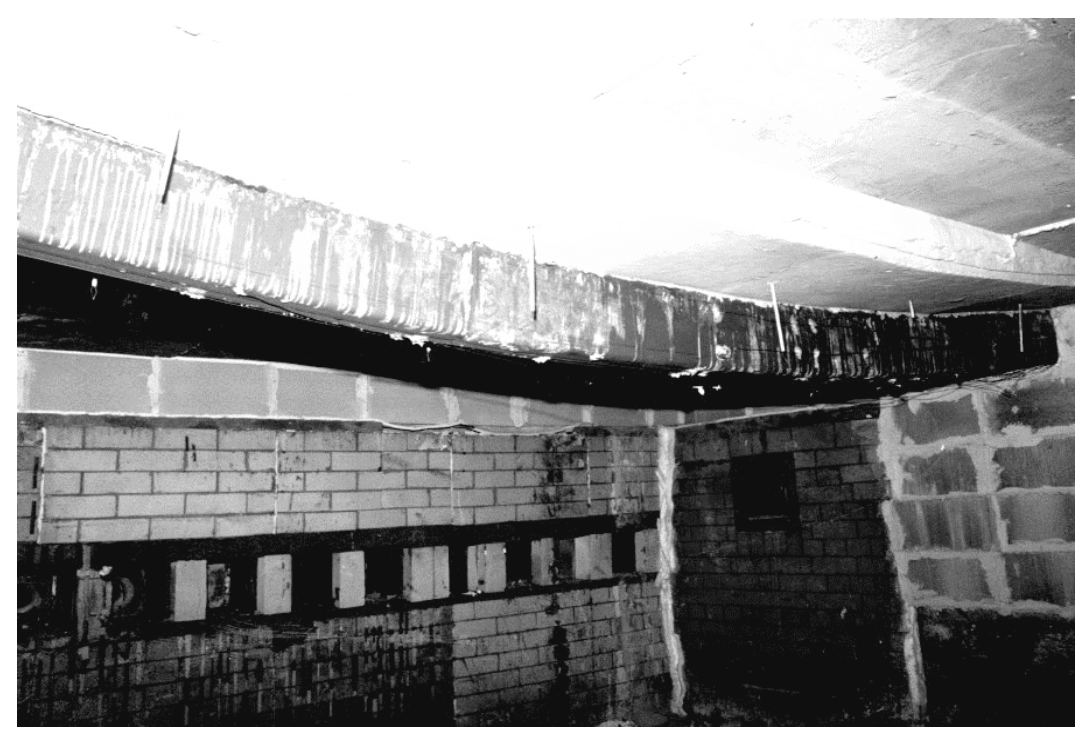

Fig. $6-200 \times 125 \times 6.0$ RHS beam after testing

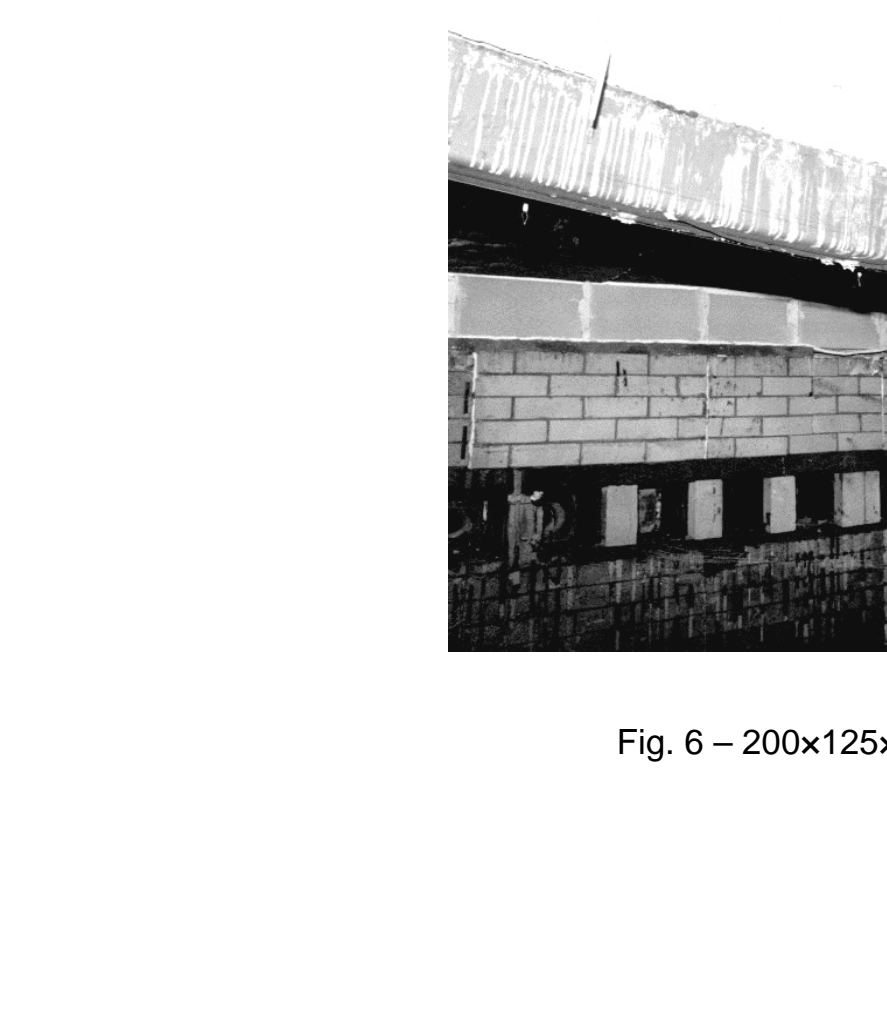


Fig. 7: Undeformed finite element stub column model

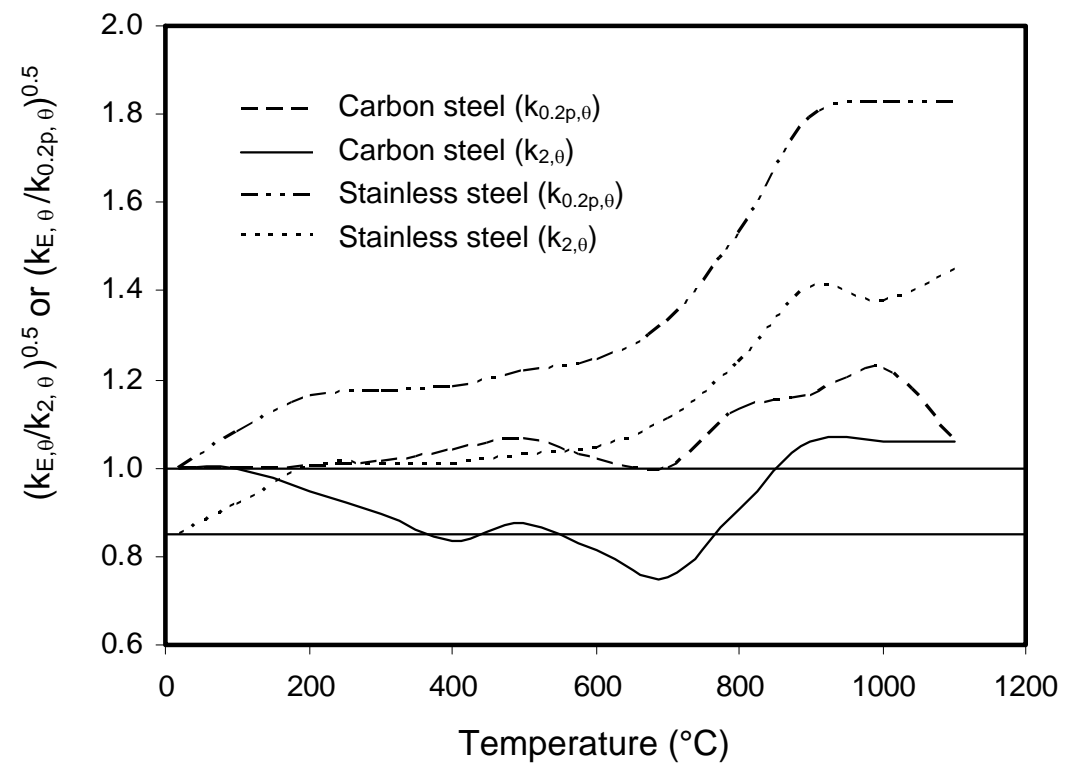

Fig. 8 - Variation of the modification factor $\left(\mathrm{k}_{\mathrm{E}, \theta} / \mathrm{k}_{2, \theta}\right)^{0.5}$ and $\left(\mathrm{k}_{\mathrm{E}, \theta} / \mathrm{k}_{0.2 \mathrm{p}, \theta}\right)^{0.5}$ with temperature

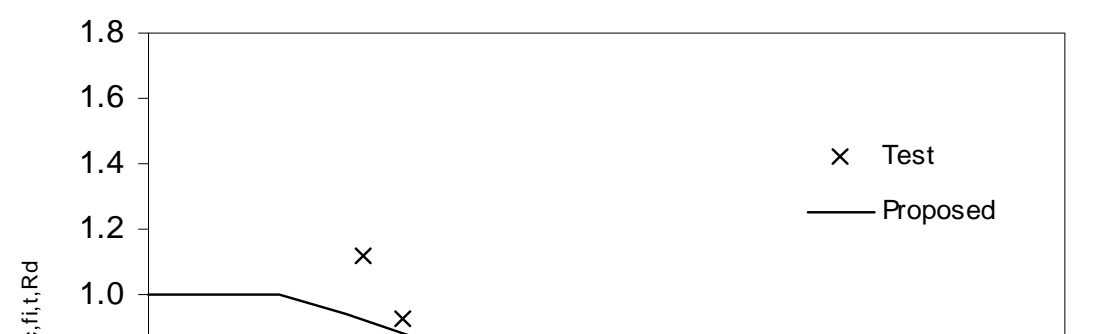


Fig. 9 - Comparison of proposed design approach with column buckling fire tests

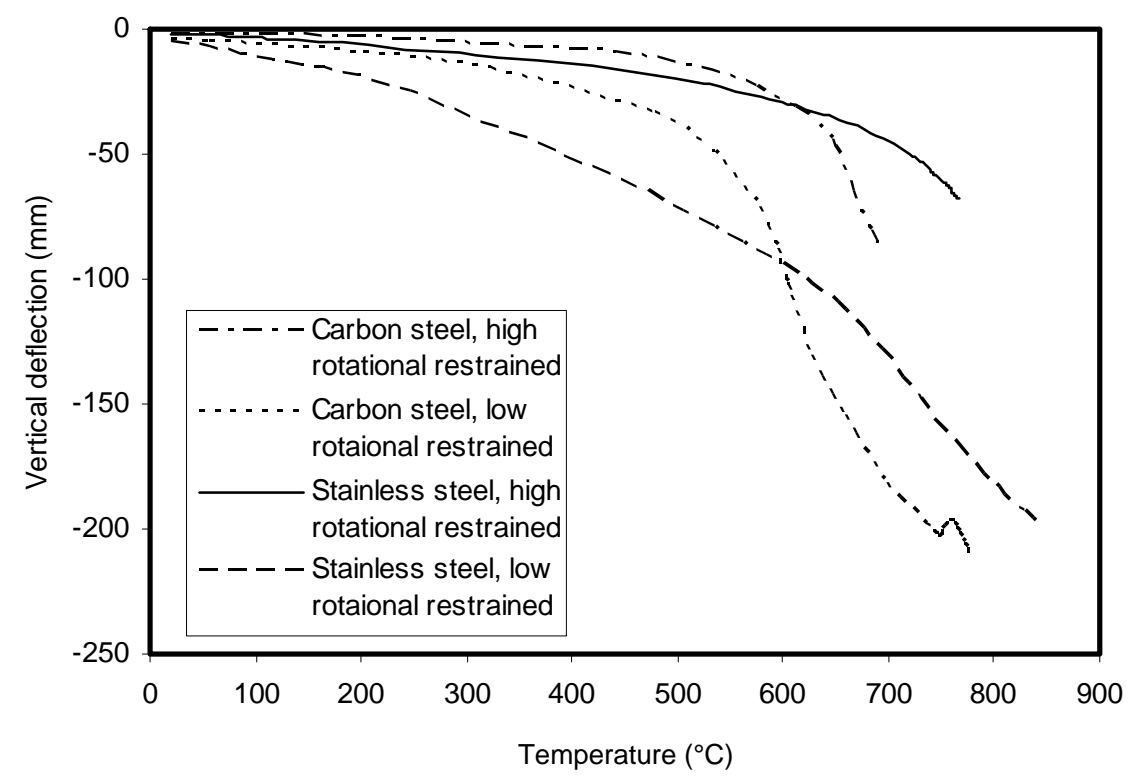

Fig. 10 - Comparison between restrained carbon steel and stainless steel beams in fire 
Table 1 - Comparison between test and FE results for column buckling

\begin{tabular}{|c|c|c|c|c|}
\hline $\begin{array}{l}\text { Nominal section size } \\
(\mathrm{mm})\end{array}$ & Load ratio & $\begin{array}{c}\text { Test critical } \\
\text { temperature }\left({ }^{\circ} \mathrm{C}\right)\end{array}$ & $\begin{array}{c}\text { FE critical } \\
\text { temperature }\left({ }^{\circ} \mathrm{C}\right)\end{array}$ & FE/Test \\
\hline RHS $150 \times 100 \times 6^{a}$ & 0.38 & 801 & 734 & 0.92 \\
\hline RHS $150 \times 75 \times 6^{a}$ & 0.25 & 883 & 819 & 0.93 \\
\hline RHS $100 \times 75 \times 6^{a}$ & 0.36 & 806 & 754 & 0.94 \\
\hline$]\left[200 \times 150 \times 6^{a}\right.$ & 0.47 & 571 & 661 & 1.16 \\
\hline RHS $100 \times 100 \times 4^{a}$ & 0.51 & 835 & 747 & 0.89 \\
\hline RHS $200 \times 200 \times 4^{a}$ & 0.45 & 820 & 696 & 0.85 \\
\hline RHS $40 \times 40 \times 4(T 1)^{b}$ & 0.24 & 873 & 736 & 0.84 \\
\hline RHS $40 \times 40 \times 4(T 2)^{b}$ & 0.70 & 579 & 505 & 0.87 \\
\hline RHS $40 \times 40 \times 4(T 3)^{b}$ & 0.62 & 649 & 597 & 0.92 \\
\hline RHS $40 \times 40 \times 4(T 4)^{b}$ & 0.52 & 710 & 633 & 0.89 \\
\hline RHS $40 \times 40 \times 4(T 5)^{b}$ & 0.30 & 832 & 720 & 0.87 \\
\hline RHS $40 \times 40 \times 4(T 7)^{b}$ & 0.41 & 766 & 675 & 0.88 \\
\hline \multicolumn{4}{|l|}{ Mean: } & 0.91 \\
\hline
\end{tabular}

Notes: ${ }^{a}$ Tests reported in [7] and [16]

${ }^{b}$ Tests reported in [20]

Table 2 - Comparison between stub column test and FE results

\begin{tabular}{|c|c|c|c|c|}
\hline $\begin{array}{l}\text { Nominal section size } \\
(\mathrm{mm})\end{array}$ & Load ratio & $\begin{array}{c}\text { Test critical } \\
\text { temperature }\left({ }^{\circ} \mathrm{C}\right)\end{array}$ & $\begin{array}{c}\text { FE critical } \\
\text { temperature }\left({ }^{\circ} \mathrm{C}\right)\end{array}$ & FE/Test \\
\hline RHS $200 \times 200 \times 5$ & 0.62 & 610 & 488 & 0.80 \\
\hline RHS $200 \times 200 \times 5$ & 0.50 & 690 & 657 & 0.95 \\
\hline RHS $200 \times 200 \times 5$ & 0.41 & 775 & 737 & 0.95 \\
\hline RHS $150 \times 150 \times 3$ & 0.63 & 590 & 567 & 0.96 \\
\hline RHS $150 \times 150 \times 3$ & 0.51 & 680 & 710 & 1.04 \\
\hline RHS $150 \times 150 \times 3$ & 0.42 & 720 & 777 & 1.08 \\
\hline \multicolumn{4}{|l|}{ Mean: } & 0.96 \\
\hline
\end{tabular}


Table 3 - Prediction of stub column critical temperature using Eurocode and proposed approach

\begin{tabular}{|c|c|c|c|c|c|c|c|c|c|}
\hline \multirow{3}{*}{ Stub column } & \multirow{3}{*}{$\begin{array}{c}\text { Plate } \\
\text { b/t ratio }\end{array}$} & \multicolumn{8}{|c|}{$\begin{array}{l}\text { Predicted (EC3 and proposed method) stub column resistance at } \\
\text { critical temperature normalised by test (or FE) applied load }\end{array}$} \\
\hline & & \multicolumn{2}{|c|}{0.3 load ratio $^{\mathrm{a}}$} & \multicolumn{2}{|c|}{0.4 load ratio $^{a}$} & \multicolumn{2}{|c|}{0.5 load ratio ${ }^{a}$} & \multicolumn{2}{|c|}{0.6 load ratio $^{\mathrm{a}}$} \\
\hline & & EC3 & Proposed & EC3 & Proposed & EC3 & Proposed & EC3 & Proposed \\
\hline SHS $200 \times 200 \times 5$ - Test & 40 & - & - & 0.61 & 0.81 & 0.66 & 0.83 & 0.63 & 0.76 \\
\hline SHS $200 \times 200 \times 5-F E$ & 40 & 0.90 & 0.96 & 0.87 & 0.95 & 0.77 & 0.90 & 0.58 & 0.75 \\
\hline SHS $200 \times 200 \times 4-F E$ & 50 & 0.89 & 0.97 & 0.86 & 0.94 & 0.76 & 0.89 & 0.56 & 0.76 \\
\hline SHS $200 \times 200 \times 3-F E$ & 67 & 0.89 & 0.97 & 0.85 & 0.95 & 0.76 & 0.92 & 0.59 & 0.81 \\
\hline SHS $150 \times 150 \times 3$ - Test & 50 & - & - & 0.85 & 1.13 & 0.77 & 1.00 & 0.75 & 0.93 \\
\hline SHS $150 \times 150 \times 3-F E$ & 50 & 0.90 & 0.97 & 0.86 & 0.94 & 0.76 & 0.90 & 0.57 & 0.77 \\
\hline SHS $150 \times 150 \times 2-F E$ & 75 & 0.90 & 0.98 & 0.87 & 0.97 & 0.78 & 0.95 & 0.61 & 0.86 \\
\hline SHS $150 \times 150 \times 1-F E$ & 150 & 0.88 & 0.97 & 0.84 & 0.95 & 0.74 & 0.90 & 0.55 & 0.79 \\
\hline \multicolumn{2}{|l|}{ Mean: } & 0.89 & 0.97 & 0.83 & 0.96 & 0.75 & 0.91 & 0.61 & 0.80 \\
\hline
\end{tabular}

Note: ${ }^{a}$ Load ratios are approximate for tests. Accurate values are given in Table 2.

Table 4 - Comparisons of critical temperatures for axially restrained columns

\begin{tabular}{l|ccc}
\hline \multirow{2}{*}{$\begin{array}{l}\text { Axial restraint } \\
\text { R (× EA/L) }\end{array}$} & \multicolumn{3}{|c}{ Critical Temperature $\left({ }^{\circ} \mathrm{C}\right)$} \\
\cline { 2 - 4 } & $\begin{array}{c}\text { Franssen } \\
\text { model [29] }\end{array}$ & Carbon Steel & Stainless steel \\
\hline Infinite & 550 & 519 & 418 \\
0.1 & 550 & 518 & 418 \\
0.05 & 550 & 519 & 420 \\
0.02 & 550 & 519 & 471 \\
0.01 & 590 & 563 & 625 \\
0 & 652 & 607 & 807 \\
\hline
\end{tabular}

